\title{
Real Time detections of Drowsy Driver using Renesas Micro Controller
}

\author{
Anusha $\mathrm{V} \mathrm{A}^{\mathbf{1}}$, Priyanka B $\mathrm{H}^{2}$, Savitha $\mathbf{N}^{3}$, Shreevandana A $\mathbf{S}^{4}$, Neelaja $\mathrm{K}^{\mathbf{5}}$ \\ Student, Computer Science \& Engineering, NIE Institute of Technology, Mysore, India ${ }^{1,2,3,4}$ \\ Assistant Professor, Dept of Computer Science \& Engineering, NIE Institute of Technology, Mysore, India ${ }^{5}$
}

\begin{abstract}
Now a days the death injuries are increased as the rate of road accidents are more. One of the main cause is due to driver fatigue. In this paper the detection of drowsy driver is based on closed or opened eye condition and displaying warning message accordingly. Detection of closed and opened eye condition is done by observing the blink pattern and eye movement. Real time detection of driver's eyes is to be processed using image processing in MATLAB to detect weather the eye remains closed for more than fixed duration which indicates the condition of fatigue and raises an alarm which could prevent a collision. Even though if the driver is drowsy, continues alarm raises, if number of raised alarm crosses certain limit then the vehicle will be made to slowdown and stopped.
\end{abstract}

Keywords: Driver drowsiness, Eye blink pattern, Eye moment, Mean.

\section{INTRODUCTION}

India's population is $1 / 6$ th of world population. The development of a country depends on its youth population, in this segment India is on top but still not completely developed. Lot of problems were facing which restricting development of the country. One such problems is Road accidents. National Highway Traffic Safety Administration [1] analysis data indicates that drowsiness while driving is a contributing factor for road accidents and it results in 4-6 times higher crash risk relative to alert drivers. Many accidents occur due to the manual error and more so due to fatigue. The major contributing factor in most accidents particularly fatal is due to driver fatigue. According to report presented by Ministry of Road Transport and Highways Government of India in 2011 country saw 4 lakh road accidents which is 1 accident per minute.

Resulting many deaths in the year 2011[2]. Up to $20 \%$ of fatal crashes may be linked to driver fatigue, later research indicates that driver fatigue could be a contributory factor up to a fifth of driver deaths. This calls for the development of a device to alert the driver, if not control the vehicle automatically. Because of the hazard that drowsiness present on the road, methods need to be developed for counteracting its affects. The focus may be placed on designing a system that will accurately monitor the open or closed state of the driver's eyes.

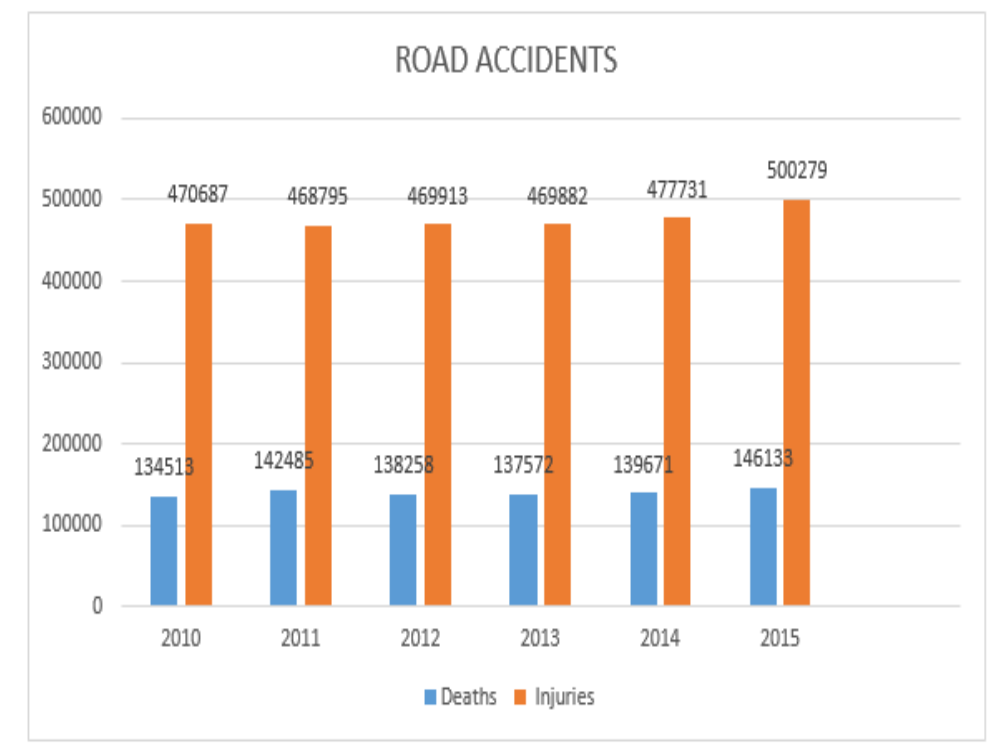

Fig 1: Road accidents statistics 
Vol. 6, Issue 5, May 2017

\section{RELATED WORKS}

Table 1: List of existing methods

\begin{tabular}{|c|c|c|c|}
\hline JOURNAL & TITLE OF THE PAPER & METHOD & DRAWBACKS \\
\hline $\begin{array}{l}\text { National } \\
\text { academyof } \\
\text { science [US]. } \\
1994\end{array}$ & $\begin{array}{l}\text { [1] WW Wierwille, et.al } \\
\text { proposed a method based on } \\
\text { Research on vehicle-based driver } \\
\text { status/performance } \\
\text { monitoring:development, } \\
\text { validation, and refinement of } \\
\text { algorithms for detection of driver } \\
\text { drowsiness [3]. }\end{array}$ & $\begin{array}{l}\text { This system proposed a } \\
\text { method to } \text { monitoring } \\
\text { changes in physiological } \\
\text { characteristics to estimate } \\
\text { driver fatigue.Is processed } \\
\text { using ECG, EEG, skin } \\
\text { temperature and head } \\
\text { movements. }\end{array}$ & $\begin{array}{l}\text { It causes distraction, non- } \\
\text { realistic and disturbance to } \\
\text { the driver. }\end{array}$ \\
\hline $\begin{array}{l}\text { IEEE } \\
\text { international } \\
\text { conference on } \\
\text { networking }, \\
\text { sensing \& } \\
\text { control 2004 }\end{array}$ & $\begin{array}{l}\text { [2] HWen-Bing,et.al proposed a } \\
\text { method based on Driver fatigue } \\
\text { detection on eye tracking and } \\
\text { dynamic template matching [4]. }\end{array}$ & $\begin{array}{l}\text { This system is based on } \\
\text { combination of projection } \\
\text { and geometry feature of iris } \\
\text { and pupil }\end{array}$ & $\begin{array}{l}\text { The drawback of this } \\
\text { method is low accuracy in } \\
\text { matching and inefficiency } \\
\text { in search. }\end{array}$ \\
\hline $\begin{array}{l}\text { Ieee } \\
\text { computer } \\
\text { society.org. } \\
2006\end{array}$ & $\begin{array}{l}\text { [3] Z Zhang, J.S Zhang et.al } \\
\text { proposed a method based on } \\
\text { Driver fatigue detection based on } \\
\text { intelligent vehicle control [5]. }\end{array}$ & $\begin{array}{l}\text { Proposed System is based on } \\
\text { Real-time eye tracking } \\
\text { method based on unscented } \\
\text { kalman filter. }\end{array}$ & $\begin{array}{l}\text { It does not stop the vehicle } \\
\text { instead maintains set slow } \\
\text { speed hence it cannot } \\
\text { control traffic overheads. }\end{array}$ \\
\hline $\begin{array}{l}\text { Ieeexplore.iee } \\
\text { e.org. } \\
2008\end{array}$ & $\begin{array}{l}\text { [4] Boyraz.P, et.al proposed a } \\
\text { method based on Sensing of } \\
\text { Vehicle response [6]. }\end{array}$ & $\begin{array}{l}\text { This system proposed a } \\
\text { method of sensing vehicle } \\
\text { response to measure } \\
\text { uncertainty in steering wheel. }\end{array}$ & $\begin{array}{l}\text { The drawback of this } \\
\text { approach is, it is driver s } \\
\text { face and monitors face and } \\
\text { eyes to detect limited to } \\
\text { vehicle type and driver } \\
\text { condition. }\end{array}$ \\
\hline $\begin{array}{l}\text { ieeexplore.iee } \\
\text { e.org. } \\
2009\end{array}$ & $\begin{array}{l}\text { [4] PR Tabrizi, et.al proposed a } \\
\text { method based on drowsiness } \\
\text { detection based on brightness and } \\
\text { numeral features of eye image } \\
\text { [7]. }\end{array}$ & $\begin{array}{l}\begin{array}{l}\text { This system method is to } \\
\text { process } \\
\text { electrocardiogram } \\
\text { signals of driver. }\end{array} \\
\text { (ECG) }\end{array}$ & $\begin{array}{l}\text { This approach has } \\
\text { limitation as ECG probes } \\
\text { shall always be connected } \\
\text { to driver's body. That } \\
\text { would disturb the driver. }\end{array}$ \\
\hline $\begin{array}{l}\text { IJITCS } \\
2016\end{array}$ & $\begin{array}{l}\text { [6] Artaud, et.al proposed a } \\
\text { method based on Monitoring the } \\
\text { response of drivers [8]. }\end{array}$ & $\begin{array}{l}\text { In this proposed a method of } \\
\text { sensing driver response by } \\
\text { placing sensor and steering } \\
\text { wheel and back of seat. }\end{array}$ & $\begin{array}{l}\text { It fails if driver wears } \\
\text { gloves and performance of } \\
\text { sensor placed on back seat } \\
\text { reduces with time. }\end{array}$ \\
\hline
\end{tabular}

All the above existing method are intrusive and non-intrusive system of driver fatigue detection system. Few drawbacks that are noticed here are system is complex and cannot be placed easily hence it causes disturbance, poor performance, non-reliable and produces noise. Many researchers are done to overcome these problems and few have been reported [9] [10] [11] [12] [13] [14].The solution for these drawbacks using non-intrusion system is contributed in this paper.

\section{PROPOSED WORK}

Driver fatigue is detected based on face analysis and the status of eyes with the help of Mean. If the Mean less than the driver alerted. In this system we are using non-introduction method.

The proposed algorithm is implemented using Embedded $\mathrm{C}$ and the required functions are developed using MATLAB routines. The eye state detection algorithm the basic step is face extraction and then the localization of the eyes. This is done by following one of the methods proposed by Dr.P.Sudhakar Rao, et.al. [15] this algorithm is dived into three steps:-

- Face detection and extraction.

- Eye detection and

- Eye tracking.

The performance of each steps is highly dependent on the previous one as the result obtained in each step are pass on to the next step as input. 


\section{A. Detail description of proposed method:}

In the proposed method, basic step is attachingthe camera to computer or can alsouseinbuilt camera of laptop. With the help of these camera video has been captured in real time by giving a following command in the system.

Input 1=videoinput('winvideo', 1,'YUY2_320*240');

Where, 'winvideo' is used for capturing real time video by the given camera. Later video is then divided into frame by getting snap shots of the video by the following inbuilt function of MATLAB.

Input2=getsnapshot (Input1);

Later by using CascadeObjectDetector function we should detect and crop the face and from the cropped face eye is detected and cropped An image may be defined as a two dimensional function(x, y), where $\mathrm{x}$ and $\mathrm{y}$ are spatial (plane) coordinates, and the amplitude of ' $f$ ' at any pair of coordinates $(x, y)$ is called the intensity or gray level of the image at that point. When $\mathrm{x}, \mathrm{y}$ and the intensity values of $\mathrm{f}$ are all finite, discrete quantities, we call the image a digital image

i).Gray Scale Conversion- It is a process of converting grayscale image to binary image. After detecting the eye region from the input image (rgb) should be converted into gray scale by using the syntax,'rgb2gray (RGB)'which is an inbuilt function in MATLAB. It converts the original color image into grayscale intensity image. The binary image consists of only two gray levels, depending upon the threshold value denoted by $\mathrm{T}$.

$\mathrm{g}(\mathrm{x}, \mathrm{y})=0$, if $\mathrm{f}(\mathrm{x}, \mathrm{y})>\mathrm{T}$

$\mathrm{g}(\mathrm{x}, \mathrm{y})=1$, if $\mathrm{f}(\mathrm{x}, \mathrm{y})<\mathrm{T}$

Where ' 0 ' represents Black and ' 1 ' represents White. In the following image eye balls are assigned white pixel value and background is assigned with black pixel. Adaptive Thresholding is used in this algorithm, as it handles illumination problem more prominently compared to Global and Local Thresholding.

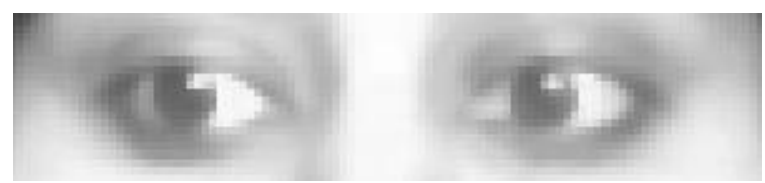

Fig 2: Grayscale image

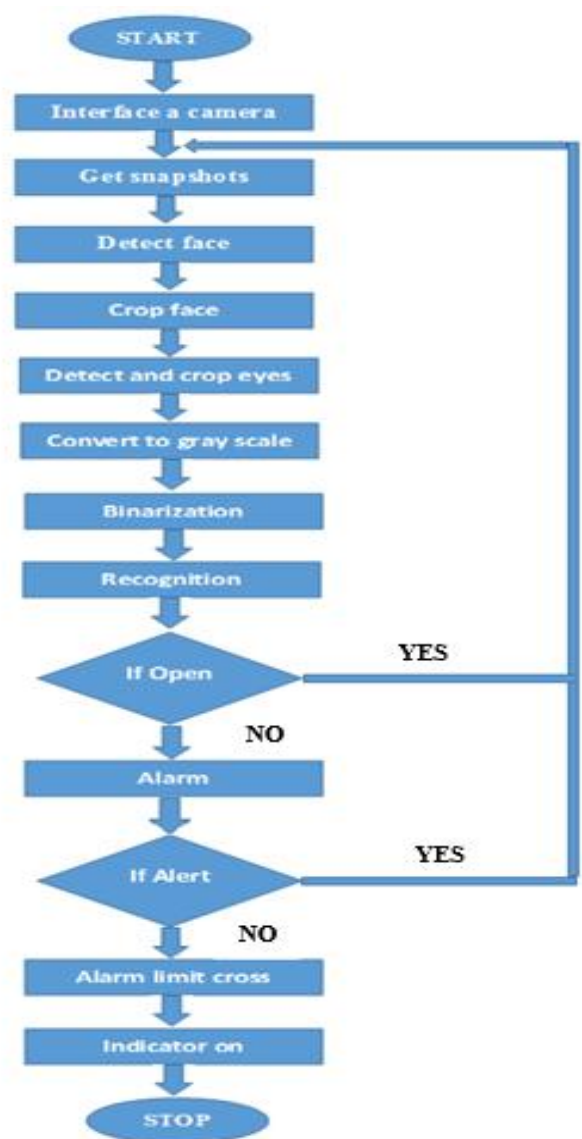

Fig 3: Flow diagram 
ii) Binarization- Is the process of converting a pixel into image. Only two colors are used for binary image that are black \& white. Binarization is performed with the inbuilt function of MATLAB where syntax'BW=im2bw (I, level)' is used these conversions are threshold based. Im $2 \mathrm{bw}$ executes or produce binary Images from RGB image that is captured by camera. The values of binary image (BW) is 0 for black and 1 for white pixels.

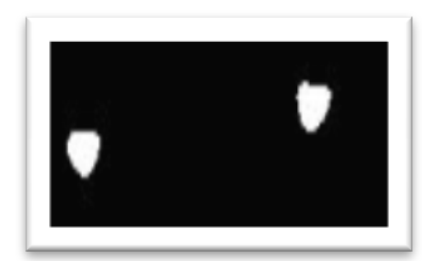

Fig 4: Binary image

iii) Recognition-In this proposed system the drowsiness detected by using Mean of the image matrix. The Mean of the matrix is calculated by using the syntax,'mean_vaule=mean2(I);'which is an inbuilt function in MATLAB.If the system found the driver is drowsy it will send signal to the controller but if the system find that the eye is opened then it is considered that the driver is not drowsy, so the system starts to capture the video again.

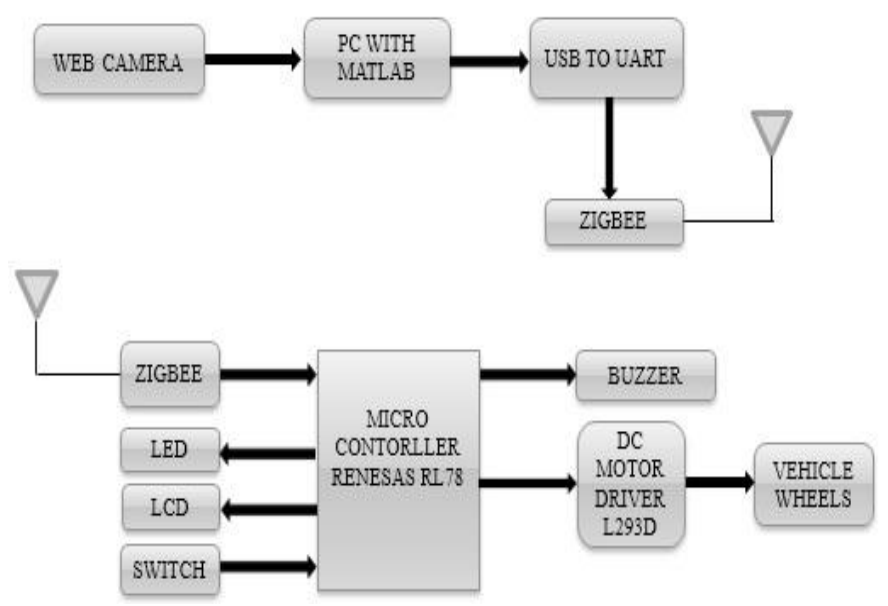

Fig 5: Block diagram

This is the final destination of proposed system, As soon as the controller receives the signal alarm is raised with the help of functions that is written using Embedded C. Here Embedded C functions are used for the working of controller and the hardware components. Later by hearing the beeping of alarm if the driver get alerted he can off the alarm with the switch provided and continue driving. In case if he neglect to turn off the switch and continuing driving beyond the alarm limit for $\mathrm{n}$ number of times, Then the controller sends the signal to LEDand DC motor asking to turn ON the Indicator and to stop the vehicle. By these we can prevent the cause of accidents.

\section{RESULT}

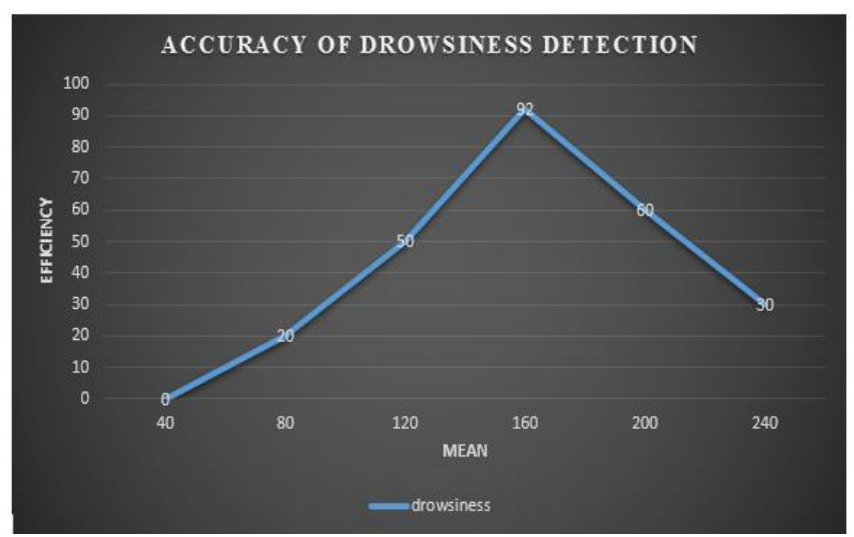

Fig 6: Accuracy of drowsiness 
In proposed system drowsiness is calculated using mean, resultant of this graph shows efficiency of the system. Where $\mathrm{x}$-axis is represents current Mean and $\mathrm{y}$-axis represents efficiency, here best efficiency of the system depends upon the threshold value in this graph it varies between the threshold values 120 to 160.

\section{CONCLUSION}

Inthis paper a new system is proposed to estimate driver fatigue using image processing technique and Embedded $\mathrm{C}$ programing. Driver fatigue is estimated based on Mean of matrix. If the Mean value is less than current Mean value than the driver is entering into drowsiness and driver is alerted by raising the alarm and the vehicle is stopped. The face and eye are detected using CascadeObjectDetector. Eye Open or Close is estimated using counting the number of white pixels.

The proposed system will overcome the problems that associated with the existing systems has it helps to detect the drowsiness in real time scenario.

\section{REFERENCES}

[1] Manisha Ruikar, National statistics of road traffic accidents in India, March 28, 2016

[2] "Road accidents in India Issues and dimensions", Ministry of Road Transport and Highway Government of India, 2012.

[3] W. W. Wierwille, S. S. Wreggit, C. L. Kirn, L. A. Ellsworth, and R. J. Fairbanks III, "Research on vehicle-based driver status/performance monitoring: development, validation, and refinement of algorithms for detection of driver drowsiness," National Highway Traffic Safety Administration, U.S. DOT Tech Report No. DOT HS 808 247, 1994.

[4]H Wen-Bing, C Chih-Yuan, C Yi, F Chun-Hai, Driver fatigue detection based on eye tracking and dynamic template matching. Proceeding of the 2004 IEEE International Conference on Networking, Sensing \& Control (Taipei, Taiwan, 2004)

[5] Z Zhang, J-S Zhang, Driver fatigue detection based intelligent vehicle control. Paper presented at The 18th IEEE International Conference on Pattern Recognition (2006)

[6] Boyraz.P., Leicester, Hansen J.H.L, Sensing of Vehicle response, 2008.

[7]PR Tabrizi, RA Zoroofi, Drowsiness detection based on brightness and numeral features of eye image. Fifth International Conference on Intelligent Information Hiding and Multimedia Signal Processing, 2009. IIH-MSP'09, 1310-1313 (2009)

[8] Artaud et.al-1994, Mabbott et.al,-1999, Lavergne et.al, 1996, Vitabile et.al,2007-08, Eskandarian.A \& R.Sayed in 2005, "Monitoring the response of drivers.

[9] Mihir Jain, Suman K.Mitra, Naresh D.Jotwani, Eye detection using line edge MAP template.

[10] Jeffrey Huang, David Lie, Xuhui Shao, Harry Wechsler, Pose Discrimination and Eye Detection using SVM.

[11] Zhiwei Zhu, Quing Ji, Robust real time eye detection and tracking under variable lighting conditions and various face orientations, Preprint submitted to Elseiver Science, July 5, 2004.

[12] Qiong Wang, Jingyu Yang, Eye detection in facial images with unconstrained background, Journal of patternrecognition research 1, 2006, published 25 sep 2006, pp.55-62.

[13] Qiong Wang, Jingyu Yang, Eye location \& eye state detection in facial images with unconstrained background, Journal of information and computing science, Vol.1, No.5, 2006,pp.284-289.

[14] Peng Wang, Matthew B, Green, Qiang Ji, James Wayman,Automatic Eye detection and its Validation,

[15]P.Sudhakar Rao, Vijayalaxmi, S.Sreehari, "New procedure for Segmenting Eyes from human Face", International Journal of Emerging Technologies and Applications in Engineering, Technology and Sciences, ISSN:0974-3588 July-Dec, Volume 4,Issue 2,(2011). 